\title{
Induction of Labor in Post-Term Nulliparous and Parous Women - Potential Advantages of Misoprostol over Dinoprostone
}

\author{
Geburtseinleitung bei übertragenen Schwangerschaften in Nulliparae \\ und Parae - mögliche Vorteile von Misoprostol gegenüber Dinoproston
}

Authors

Affiliations
P. Tsikouras ${ }^{1}$, Z. Koukouli ${ }^{1}$, B. Manav ${ }^{1}$, M. Soilemetzidis ${ }^{1}$, A. Liberis ${ }^{1}$, R. Csorba ${ }^{2}$, G. Trypsianis ${ }^{3}$, G. Galazios ${ }^{1}$

Department of Obstetrics and Gynecology, Democritus University of Thrace, Greece

${ }^{2}$ Department of Obstetrics and Gynecology, Clinicum Aschaffenburg, Teaching Hospital of University Würzburg, Germany

Department of Medical Statistic, Democritus University of Thrace, Greece
Key words

- misoprostol

- dinoprostone

- labor induction

post-term pregnancy

Schlüsselwörter

- Misoprostol

- Dinoproston

- Geburtseinleitung

- übertragene Schwangerschaft

\section{received 24.12.2015 \\ revised 19.2.2016 \\ accepted 20.3.2016}

\section{Bibliography}

Dol http://dx.doi.org/

10.1055/s-0042-105287

Geburtsh Frauenheilk 2016; 76:

785-792 @ Georg Thieme

Verlag KG Stuttgart · New York .

ISSN 0016-5751

Correspondence
Associate Professor
Panagiotis Tsikouras
Department of Obstetrics
and Gynecology
Democritus University
of Thrace, Greece
Lysimachou/Petrina
6 Km Alexandroupolis/Makri
Box 106
68100 Alexandroupolis
Greece
ptsikour@med.duth.gr

\section{Abstract}

\section{$\nabla$}

Introduction: We undertook a prospective cohort study to compare the effectiveness and safety of $50 \mu \mathrm{g}$ misoprostol versus $3 \mathrm{mg}$ dinoprostone in two vaginal doses 6 hours apart, followed if necessary by oxytocin for labor induction in low-risk post-term (> 40 weeks) pregnancies with unfavorable cervix (Bishop score $\leq 6$ ).

Methods: Labor induction and subsequent management were conducted using a standardized protocol. The primary outcome of the study was labor induction rate. Secondary outcomes included mode of delivery, time interval from induction to delivery, maternal complications and neonatal outcome.

Results: 107 patients received misoprostol (Group A) and 99 patients received dinoprostone (Group B). Compared with group A, more women in Group B needed a second vaginal dose of prostaglandin or oxytocin infusion in order to proceed to labor ( 21.5 vs. $43.4 \%$; $=0.01$ ). Misoprostol alone as a single or double vaginal dose was more effective than dinoprostone alone in inducing labor without oxytocin administration (85.0 vs. $50.4 \% ; p=0.04$ ). Overall, the rate of successful induction of labor did not differ between groups (91.6 vs. 85.8\%; p = 0.75). Vaginal delivery, operative vaginal delivery and Caesarean section rates were not significantly different. Time interval from induction to delivery however, was shorter for Group A (median 11 hours vs. 14.1 hours; $\mathrm{p}<0.001$ ). Though emergency Caesarean section due to fetal distress was more frequent in Group A (16.8 vs. $4.0 \%$; $=0.007$ ), low Apgar scores $<7$ and NICU admissions did not differ significantly. Maternal complications, mostly not serious, were higher in Group A (31.8 vs. 2.0, p < 0.001).

Conclusion: Misoprostol is a more effective agent than dinoprost in post-term pregnancy for labor induction with few maternal adverse effects.

\section{Zusammenfassung \\ $\nabla$}

Einleitung: Das Ziel dieser prospektiven Kohortenstudie war, die Wirksamkeit und Sicherheit

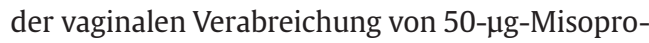
stol-Tabletten im Vergleich zu 3-mg-Prostaglandin-E2-Dinoproston-Tabletten in 2 vaginalen Dosen mit 6 Stunden Abstand und anschließender Oxytocin-Verabreichung zur Geburtseinleitung (falls erforderlich) bei übertragenen Niedrig-Risiko-Schwangerschaften (> 40 Wochen) mit unreifer Zervix (Bishop-Score $\leq 6$ ) zu untersuchen.

Patientinnen und Methode: Die Geburtseinleitung und das sich anschließende Geburtsmanagement wurden nach einem standardisierten Protokoll durchgeführt. Das primäre Ziel der Studie war die Bestimmung der Geburtseinleitungsrate. Sekundäre Endpunkte waren die Auswertung des Geburtsmodus, des Zeitintervalls von der Induktion bis zur Geburt, der mütterlichen Morbidität und des Neugeborenenstatus.

Ergebnisse: 107 Patienten erhielten Misoprostol (Gruppe A) und 99 Patienten Dinoproston (Gruppe B). Im Vergleich zu Gruppe A benötigten mehr Studienteilnehmerinnen der Gruppe B eine 2. vaginale Prostaglandin-Dosis oder Oxytocin-Infusion für den Geburtsverlauf (21,5 vs. 43,4\%; $\mathrm{p}=0,01$ ). Misoprostol allein als vaginale Einzeloder Doppeldosis war wirksamer als Dinoproston allein zur Geburtseinleitung ohne Oxytocin-Verabreichung ( 85,0 vs. $50,4 \% ; p=0,04$ ). Insgesamt wurde kein Unterschied bezüglich der Erfolgsrate bei der Geburtseinleitung zwischen den beiden Studiengruppen festgestellt (91,6 vs. $85,8 \%$; $\mathrm{p}=0,75$ ). Es gab keinen signifikanten Unterschied bei Spontanentbindungs-, operativen vaginalen Entbindungs- und Kaiserschnittraten zwischen den beiden Gruppen. Das Zeitintervall von der Induktion bis zur Geburt war jedoch kürzer in Gruppe A (Median 11 vs. 14,1 Stunden; p < 0,001). Obwohl Notfallkaiserschnitte aufgrund fetaler kardiotokografisch pathologischer Befunde in 
Gruppe A häufiger durchgeführt wurden (16,8 vs. 4,0\%, $\mathrm{p}=0,007$ ), unterschieden sich pathologische Apgar-Werte von $<7$ und Aufnahmen auf der Neugeborenenintensivstation dennoch nicht wesentlich. Die Anzahl (größtenteils leicht zu therapierender) mütterlicher Komplikationen war in Gruppe A höher (31,8 vs. $2,0, \mathrm{p}<0,001)$.

Schlussfolgerung: Bei übertragenen Schwangerschaften ist Misoprostol ein wirksameres Mittel zur Geburtseinleitung als Dinoproston und mit geringen mütterlichen Nebenwirkungen verbunden.

\section{Introduction}

\section{$\nabla$}

Induction of labor, that is the intentional initiation of labor before spontaneous onset, is a common practice that accounts for $20 \%$ of all births [1]. Today, that significant concern on overuse of Caesarean delivery exists [2], induction of labor for specific indications, particularly for post-term pregnancies, seems even more important as it can lower the risk of Caesarean section [3]. A number of methods to promote labor induction are used today, including mechanical methods (membrane stripping or sweeping, cervical balloon, amniotomy) and pharmacological agents (prostaglandins such as dinoprostone, $\mathrm{PGE}_{2}$, misoprostol $\mathrm{PGE}_{1}$, mifepristone or oxytocin) $[4,5]$. Conventionally, labor is induced by oxytocin in patients with a favorable cervix. In the presence of an unfavorable cervix (low Bishop score), however, prostaglandin works efficiently in cervical ripening and labor induction [6]. A considerable number of prospective trials have compared prostaglandin analogues at different dosages and administration routes with placebo, with oxytocin or with each other [7-13].

Dinoprostone is a naturally occurring prostaglandin E2 ( $\left.\mathrm{PGE}_{2}\right)$. It is widely used in obstetrics, in gel or tablet form, for vaginal application. Dinoprostone is the only prostaglandin agent approved by the US Food and Drug Administration (FDA) for labor induction in nulliparous or parous women with singleton post-term pregnancies [6]. Misoprostol is a synthetic prostaglandin E1 analogue that was developed in 1973 for the prevention or treatment of peptic ulcer [14]. Its undisputed ability to bring on uterine contractions has led to it being evaluated as a means of labor induction since 1993. Currently, misoprostol is licensed by FDA only for the prevention of nonsteroidal anti-inflammatory druginduced gastric ulcers and for medical abortion in combination with mifepristone. However, it is widely used off-label for a variety of indications in obstetrics and gynecology, including medical abortion, medical management of miscarriage, cervical ripening before surgical procedures, and the treatment of postpartum hemorrhage [14]. Though unlicensed by National Drug Organizations, misoprostol is also currently used in most of the European countries as a labor induction agent [5]. In Switzerland in 2011 a total of $78 \%$ of obstetricians reported the use of misoprostol for labor induction, although it is not licensed [15]. In a similar study in Germany 66\% of obstetricians reported off label use of misoprostol for labor induction in 2013 [16]. In Greece, misoprostol use in obstetrics has no approval by the National Drug Organization (EOФ), but Hellenic Society of Obstetrics and Gynecologists consents to its use for labor induction in cases of intrauterine death or in clinical trials only [17]. In this context, labor induction by misoprostol remains a taboo-issue among Greek obstetricians. There are no information on the extent of this practice, while in the fear of complications and medico-legal consequences it may even go unregistered in patients' charts.
The present study was undertaken in order to compare the effectiveness and safety of vaginal administration of $50 \mu \mathrm{g}$ misoprostol versus $3 \mathrm{mg}$ dinoprostone in two doses 6 hours apart followed by oxytocin administration for labor induction in low-risk postterm pregnancies. Data were collected prospectively eight years ago, but not published until today. Although similar literature already exists, we feel that the study remains topical. First, in the on-going effort for safe reduction of the rate of primary Caesarean deliveries, we are still in search of effective ways to induce labor. Second, the issue with off-label misoprostol use for labor induction is still unresolved. Third, accumulation of evidence coming from different clinical settings may prove helpful.

\section{Methods}

$\nabla$

\section{Eligibility criteria and study design}

We undertook a prospective, cohort study on nulliparous and parous pregnant women undergoing labor induction from March 2004 to June 2007 in the Department of Obstetrics and Gynecology at the General Hospital of Xanthi, Greece. Inclusion criteria were: post term (pregnancy longer than 40 weeks), age $\geq 17$ years, singleton fetus with cephalic presentation, intact membranes, unfavorable cervical Bishop score $(\leq 6)$ and absence of spontaneous uterine contractions. Exclusion criteria were: ruptured membranes, suspected chorioamnionitis or other serious infection, previous Caesarean section, history of uterine fibroid removal, obstetric risk factors such as uterine abnormality, severe preeclampsia/HELLP with elevated liver enzymes, central nervous system involvement, current genital infection, intolerance to prostaglandins, hemoglobin less than $8 \mathrm{mg} / \mathrm{dl}$. We obtained approval by the institutional ethics committee and all eligible patients gave their written consent after receiving relevant information including the potential adverse effects of medical labor induction.

The induction agents compared were misoprostol at a dosage of $50 \mu \mathrm{g}$ or dinoprostone at a dosage of $3 \mathrm{mg}$, both administered vaginally and followed if necessary by oxytocin administration. Labor induction and subsequent management were conducted using a standardized protocol, which determined the administration of pharmacological agents at predefined time intervals and sequence according to specified criteria. The study population was divided in two groups, according to the induction agent administered - participants in Group A received misoprostol and participants in Group B received dinoprostone. The choice of induction agent was made by the attending obstetrician in an arbitrary way, however there was no formal randomization process. The study was open-label. The primary outcome of the study was labor induction rate. Secondary outcomes included mode of de- 


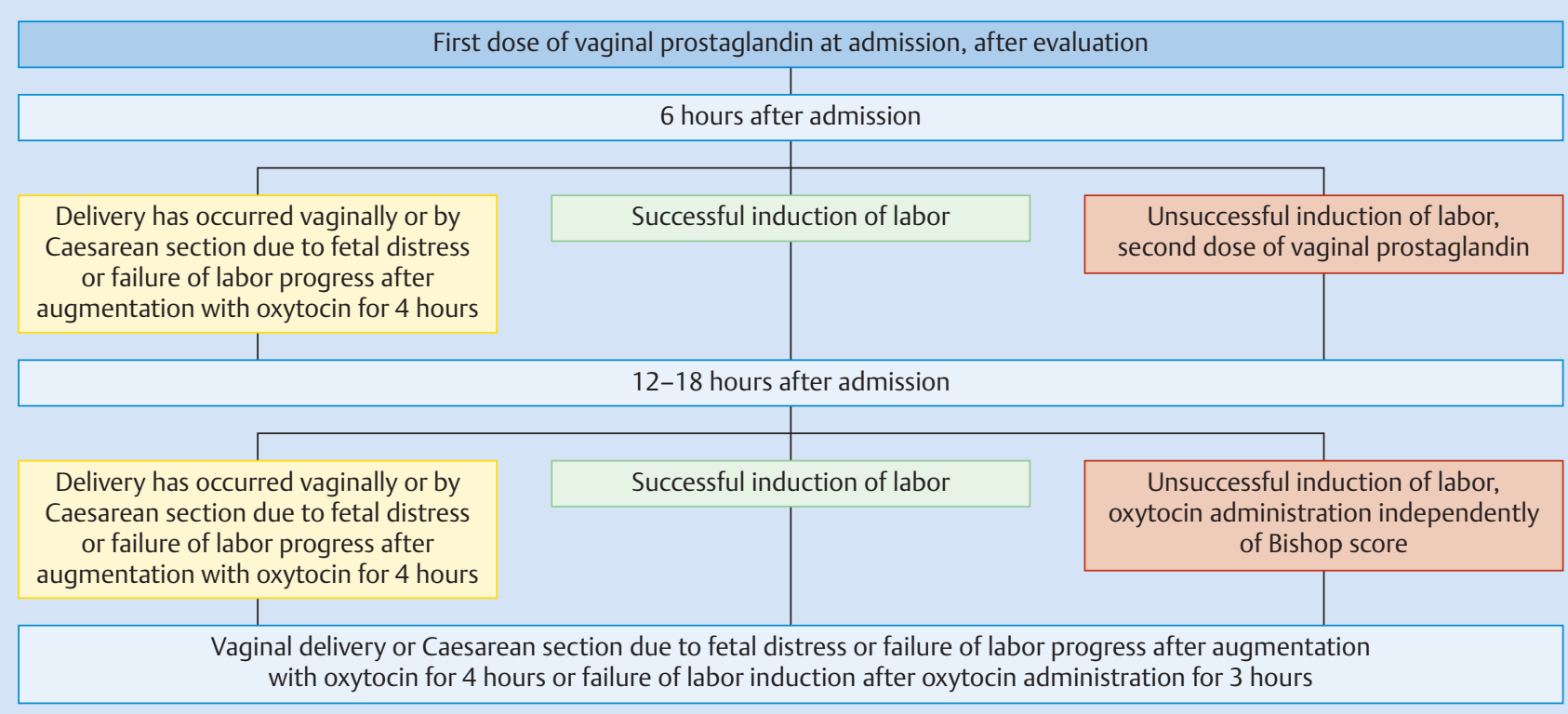

Fig. 1 Study protocol.

livery, time interval from induction-to-delivery, maternal sideeffects/complications and neonatal outcome.

\section{Procedures}

Study protocol is presented in $\bigcirc$ Fig. 1. All study participants were admitted for labor induction and evaluated by the attending obstetrician. Gestational age was determined by the first day of the last menstrual period according to menstrual history and/ or first trimester sonography. A fetal ultrasound was performed in order to determine fetal presentation and estimated fetal weight. All women underwent cardiotocography (CTG) so as to rule out fetal distress and/or presence of uterine contractions. The cervical Bishop score was estimated on admission by the attending obstetrician and two midwifes. Any disagreements were resolved by discussion, until a consensus was reached.

Following evaluation, $50 \mu \mathrm{g}$ misoprostol were administered vaginally in Group A participants ( $1 / 4$ of a Cytotec tablet cut precisely with a pill cutter in to four homogenous doses). Group B participants received vaginally 1 tablet of $3 \mathrm{mg}$ dinoprostone (PGE2, Prostin), previously moistened with 2-3 drops of saline for injection, which was inserted in the vaginal fornix. All women remained supine for one hour following insertion. Cardiotocographic (CTG) recordings continued during the first hour of insertion and were repeated with onset of contractions. Cervical dilatation greater than $3-4 \mathrm{~cm}$ resulting from onset of contractions was considered successful induction of labor. Six hours after the administration of the pharmacological agent the vaginal examination was repeated; if labor had not been induced, a repeat vaginal dose of the agent was given and the woman was re-evaluated 6-12 hours later. Then, if labor had still not been induced, oxytocin ( 1 amp. oxytocin $5 \mathrm{IU}$ in $500 \mathrm{ml}$ dextrose $5 \%$ solution) was added independently of the Bishop Score at a starting dose of $30 \mathrm{ml}(300 \mathrm{mU}) / \mathrm{h}$, being increased $10 \mathrm{ml}(100 \mathrm{mU}) / 30 \mathrm{~min}$ until $100 \mathrm{ml}(1000 \mathrm{mU}) / \mathrm{h}$. If labor did not start within the next three hours we proceeded to Caesarean section due to failed induction, i.e. the inability to achieve cervical dilatation greater than $3 \mathrm{~cm}$ after twelve hours agent induction (misoprostol or dinoprostone) and three hours oxytocin administration [18].

Failure of labor progress, on the other hand, followed successful induction (cervical dilatation greater than $3 \mathrm{~cm}$ ) and is a general term used to include lack of progressive cervical dilatation or lack of fetal descent, commonly attributed to cephalopelvic disproportion or malposition. Arrest disorders as described by Friedman [19] were always managed with oxytocin administration using the previously reported protocol for four hours, as proposed by Rouse [20]. If no labor progress (no cervical change in the presence of adequate uterine contractions or inadequate uterine contractions with maximum oxytocin administration) was seen four hours after receiving oxytocin a Caesarean section was performed due to failure of labor progress. Finally, if at any time serious CTG pathologies were observed, a Caesarean section was performed due to fetal distress. Fetal distress patterns involved loss of variability in conjunction with severe decelerations or persistent baseline rate changes, or both. Less serious CTG abnormalities were managed with oxygen and fluid administration and change of maternal position. Amniotomy was performed routinely in all women in both groups, as soon as cervical dilatation reached $5-6 \mathrm{~cm}$. Abnormalities in contractions were coded as tachysystole and hyperstimulation. Tachysystole was defined as the appearance of at least 6 contractions in 10 minutes for two consecutive 10-minute periods, while hyperstimulation was defined by simultaneous presence of tachysystole with cardiotocographic abnormalities. CTG tracings and labor progress were reviewed and discussed by the attending obstetrician and the two midwifes. However, the decision for administration of pharmacological agents and the decision for Caesarean section was made by the physician.

\section{Statistical analysis}

Statistical analysis of the data was performed using the Statistical Package for the Social Sciences (SPSS), version 19.0 (IBM). The normality of quantitative variables was tested by the Kolmogorov-Smirnov test. Normally distributed quantitative variables 


\section{0 total births from March 2004 \\ to June 2007 in the Department of \\ Obstetrics and Gynecology at the \\ General Hospital of Xanthi, Greece \\ 340 labor inductions, all patients were assessed for inclusion}

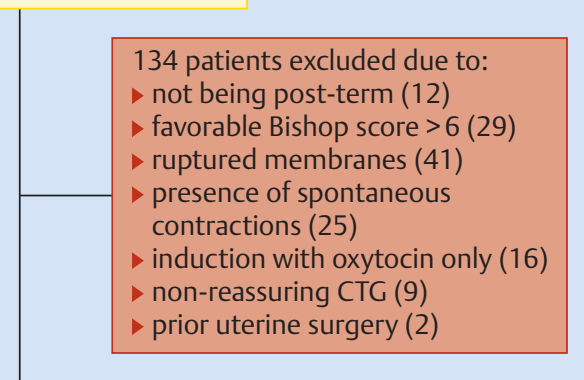

206 patients included in study

analysis and separated into two

groups according to induction agent received

\begin{tabular}{|c|c|}
\hline & \\
\hline $\begin{array}{l}50 \mu g \text { of } \\
\text { misoprostol } \\
\text { vaginally }\end{array}$ & $\begin{array}{l}3 \text { mg of } \\
\text { dinoprost } \\
\text { vaginally }\end{array}$ \\
\hline
\end{tabular}

Fig. 2 Study flow diagram.

(age) were expressed as the mean \pm standard deviation, while non-normally distributed variables (time interval between the beginning of labor induction and birth, birth weight) were expressed as the median and interquartile range (25th to 75th percentile). A comparison was made between these factors among the two groups of women by means of the Student's t-test and Mann-Whitney U-test, respectively. The $\mathrm{X}^{2}$ test or Fisher's exact test was used to express qualitative variables as frequencies and to analyze percentages. Logistic regression models were employed to estimate odd ratios (OR) and their 95\% confidence intervals $(\mathrm{CI})$ as well as any potential association of the type of drug with delivery outcome. All tests were two-tailed, while statistical significance was considered for $\mathrm{p}$ values $<0.05$.

\section{Results}

$\boldsymbol{\nabla}$

\section{Patient characteristics}

From March, 2004 to June, 2007340 primiparous and parous women underwent labor induction in our institution at a total of 3780 births. 134 patients were deemed ineligible. 206 women fulfilled the inclusion criteria and were included in the study. 107 patients received vaginally $50 \mu \mathrm{g}$ of misoprostol (Group A), while 99 patients received vaginally $3 \mathrm{mg}$ dinoprostone (Group B). The study flow diagram and detailed reasons for patient ineligibility are shown in $\odot$ Fig. 2.

The demographical and clinical characteristics of eligible patients by group are listed in 0 Table 1. No significant differences arose between baseline characteristics of patients in the two groups (age, parity, BMI). In both groups most women were primiparous. Bishop score before labor induction had a mean value about 5 in both groups. Although estimated fetal weight at admission had not been used as an exclusion criterion, in none of the participants the neonatal birth weight exceeded 4500 gr., in accordance with fetometry. Mean birth weight was not significantly different between groups.

\section{Overall analysis}

The main results of the study are presented in $\triangle$ Table 2. Labor induction was successful in 98 (91.6\%) women in Group A and $85(85.8 \%)$ women in Group B. Labor induction rate was not significantly different between groups $(\mathrm{p}$-value $=0.75$ ). Overall, 72 (67.3\%) women in Group A and 76 (76.7\%) women in group B were delivered vaginally. Operative delivery rate (6.6\% in Group A vs. $10.1 \%$ in group B) and Caesarean section rate $(32.7 \%$ in Group A vs. 23.2\% in Group B) were not significantly different between groups ( $p$-values $=0.72$ and 0.25 respectively). Failure of labor progress after successful induction was not different between groups ( $8.1 \%$ vs. $5.9 \%$; p-value $=0.57$ ). However, women in Group A compared with women in Group B had an average 5fold relative risk for fetal distress $(\mathrm{OR}=4.8,95 \% \mathrm{CI}=1.5$ to 14.7 ; $\mathrm{p}$ value $=0.007$ ). Thus, Caesarean section following successful induction of labor was more common in Group A (26.5\% vs. $10.5 \%$; p-value $=0.02$ ). Although labor induction rate and mode of delivery were similar between groups, a significant difference arose in overall analysis regarding the time interval from admission (beginning of induction) to delivery. Induction-to-delivery interval was significantly shorter in Group A patients (median 11 hours vs. 14.1 hours; p-value < 0.001 ).

\section{Single prostaglandin dose}

Labor induction rate in Group A after one dose of misoprostol was statistically significantly higher compared to women in Group B after one dose of dinoprostone (70.1\% vs. $42.4 \%$, $\mathrm{p}<0.001)$; specifically, in six hours' time after a single prosta-

Table 1 Demographical and clinical characteristics of study participants by group.

\begin{tabular}{|c|c|c|c|}
\hline & Group $A(n=107)$ & Group B $(n=99)$ & p-value \\
\hline Age (years; mean \pm SD) & $26.21 \pm 4.43$ & $26.37 \pm 4.81$ & NS \\
\hline $\mathrm{BMI}\left(\mathrm{kg} / \mathrm{m}^{2} ;\right.$ mean $\left.\pm \mathrm{SD}\right)$ & $27.52 \pm 2.98$ & $26.86 \pm 3.36$ & NS \\
\hline Smokers (no, \%) & $10(9.3)$ & $8(8.1)$ & NS \\
\hline Primiparas (no, \%) & $88(82.2)$ & $82(82.8)$ & NS \\
\hline Multiparas (no, \%) & $19(17.8)$ & $17(17.2)$ & NS \\
\hline Bishop score before labor induction (mean \pm SD) & $5.10 \pm 2.05$ & $4.75 \pm 2.52$ & NS \\
\hline Birth weight (gr; median, interquartile range) & $3542(2930-4085)$ & $3427(2820-4030)$ & NS \\
\hline
\end{tabular}


Table 2 Study results. Number of births (no, \%), mode of delivery (no, \%), induction-delivery intervals (hours; median, interquartile range), maternal side effects/ complications (no, \%) and neonatal outcomes (no, \%) by group. Logistic regression analysis with Group A as referent: Odds ratio (OR), 95\% Confidence interval (Cl)

\begin{tabular}{|c|c|c|c|c|}
\hline Overall & Group A & Group B & p-value & OR $(95 \% \mathrm{Cl})$ \\
\hline Total births & $107(100 \%)$ & $99(100 \%)$ & & \\
\hline Vaginal delivery & $72(67.3 \%)$ & $76(76.7 \%)$ & NS & \\
\hline Operative delivery & $7(6.6 \%)$ & $10(10.1 \%)$ & NS & \\
\hline Caesarean section & $35(32.7 \%)$ & $23(23.2 \%)$ & NS & \\
\hline Fetal distress & $18(16.8 \%)$ & $4(4.0 \%)$ & $0.007^{*}$ & $4.8(1.5-14.7)$ \\
\hline Failure of labor progress & $8(7.5 \%)$ & $5(5.0 \%)$ & NS & \\
\hline Failure of labor induction & $9(8.4 \%)$ & $14(14.1 \%)$ & NS & \\
\hline Induction-to-delivery interval & $11.0(5.8-16.2)$ & $14.1(9.2-19.0)$ & $<0.001^{*}$ & \\
\hline Single prostaglandin dose & Group $A(n=107)$ & Group B ( $n=99)$ & p-value & OR $(95 \% \mathrm{Cl})$ \\
\hline Successful inductions & $75(70.1)$ & $42(42.4)$ & $<0.001^{*}$ & $3.2(1.8-5.7)$ \\
\hline Vaginal delivery & $52(69.3)$ & $33(78.6)$ & NS & \\
\hline Operative delivery & $3(4.0)$ & $4(9.5)$ & NS & \\
\hline Caesarean section & $20(26.7)$ & $5(11.9)$ & 0.062 & $2.7(0.9-7.8)$ \\
\hline Induction-to-delivery interval & $8.5(4.5-13.7)$ & $8.3(5.0-12.8)$ & NS & - \\
\hline Double prostaglandin dose & Group A ( $n=32)$ & Group B $(n=57)$ & p-value & OR $(95 \% \mathrm{Cl})$ \\
\hline Successful inductions & $16(50.0)$ & $12(21.1)$ & $0.005^{*}$ & $3.8(1.5-9.6)$ \\
\hline Vaginal delivery & $10(62.4)$ & $6(50.0)$ & NS & \\
\hline Operative delivery & $3(18.8)$ & $4(33.3)$ & NS & \\
\hline Caesarean section & $3(18.8)$ & $2(16.7)$ & NS & \\
\hline Induction-to-delivery interval & $14.1(10.4-17.3)$ & $13.4(9.8-16.1)$ & NS & - \\
\hline Oxytocin administration & Group A $(n=16)$ & Group B $(n=45)$ & $\mathrm{p}$-value & OR $(95 \% \mathrm{Cl})$ \\
\hline Successful inductions & $7(43.8)$ & $31(68.9)$ & 0.075 & $0.4(0.1-1.1)$ \\
\hline Vaginal delivery & $3(42.9)$ & $27(87.0)$ & $0.010^{*}$ & $0.1(0.02-0.7)$ \\
\hline Operative delivery & $1(14.3)$ & $2(6.5)$ & NS & \\
\hline Caesarean section & $3(42.9)$ & $2(6.5)$ & $0.035^{*}$ & $10.6(1.4-86.4)$ \\
\hline Induction-to-delivery interval & $18.4(17.1-22.4)$ & $19.1(17.3-23.0)$ & NS & - \\
\hline Maternal side effects/complications & Group A & Group B & p-value & OR $(95 \% \mathrm{Cl})$ \\
\hline Uterine hyperstimulation & 0 & 0 & & \\
\hline Vomiting & $14(14.0)$ & $1(1.0)$ & $<0.001^{*}$ & $16.0(2.1-123.4)$ \\
\hline Fever $\left(>38^{\circ} \mathrm{C}\right)$ & $12(11.2)$ & $0(0.0)$ & $0.001^{*}$ & - \\
\hline Blood transfusion & $7(6.5)$ & $1(1.0)$ & 0.067 & $6.9(0.8-56.8)$ \\
\hline Neonatal outcomes & Group A & Group B & p-value & OR $(95 \% \mathrm{Cl})$ \\
\hline Apgar score $1^{\prime}<7$ & $11(10.1)$ & $8(7.4)$ & NS & \\
\hline Apgar score $5^{\prime}<7$ & $11(10.2)$ & $5(4.7)$ & NS & \\
\hline NICU transfer & $9(8.4)$ & $4(4.0)$ & NS & \\
\hline
\end{tabular}

glandin dose active labor of women in Group A was over three times more likely to begin than in Group B $(\mathrm{OR}=3.2,95 \% \mathrm{CI}=1.8$ to 5.7). Mode of delivery was not different between groups, however there was a tendency towards higher frequency of Caesarean section in Group A compared to Group B (26.7 vs. $11.9 \%$, $\mathrm{p}=0.062$ ). Among women whose labor had been successfully induced with a single prostaglandin dose there was no drug-related difference in induction-to-delivery interval (median time, $8.53 \mathrm{~h}$ in Group A vs. 8.38 h in Group B, p = 0.734 .

\section{Double prostaglandin dose}

Subsequently, women without successful induction to labor in six hours' time after a single prostaglandin dose received a second dose of misoprostol in Group A (32 out of the 107 women, $29.9 \%$ ) or dinoprostone in Group B (57 of the 99 women, 57.6\%). In twelve to eighteen hours post-admission and after a double prostaglandin dose labor induction rate in Group A was still statistically significantly higher compared to Group B (85.0 vs. $54.5 \% ; \mathrm{p}=0.04$ ). Active labor of women in Group A was almost four times more likely to begin than in Group B (OR $=3.8,95 \%$ $\mathrm{CI}=1.5$ to $9.6, \mathrm{p}=0.005$ ) in six to twelve hours after the second prostaglandin dose. No statistically significant differences were found in mode of delivery for women successfully induced into labor after a double prostaglandin dose and induction to delivery intervals were similar between the two groups (median time: 14.1 hours in Group A vs. 13.4 hours in Group B, $p=0.612$ ). Following successful induction with single- or double-dose vaginal prostaglandin an average 15\% of women in both groups $(p=0.272)$ required oxytocin augmentation for labor arrest. Of these women an average $60 \%$ in both groups $(p=0.647)$ finally underwent Caesarean section for failure of labor progress.

\section{Oxytocin administration}

Twelve to eighteen hours post-admission 16 of the 107 women (15.0\%) in Group A and 45 of the 99 women (45.5\%) in Group B received oxytocin for labor induction. At this point, and only after oxytocin administration, labor induction rate in Group B became similar to labor induction rate in Group A (overall 85.8 vs. 91.6\% as discussed). In fact, women in Group B after oxytocin administration were over six times more likely to deliver vaginally than women in Group A (OR=6.5, 95\% $\mathrm{CI}=1.6$ to $26, \mathrm{p}=0.010)$. Following successful induction with oxytocin, women in Group A compared to those in Group B were ten times more likely to have a Caesarean section due to fetal distress or failure of labor progress $(\mathrm{OR}=10.6,95 \% \mathrm{CI}=1.4$ to $86.4, \mathrm{p}=0.035)$. Induction-to-delivery intervals were similar between the two groups (median 18.4 hours in Group A vs. 19.1 hours in Group B; $\mathrm{p}=0.711$ ). Finally, for 9 (8.4\%) women in Group A and 14 (14.1\%) in Group B 
active labor did not start despite administration of oxytocin for three hours and a Caesarean section was necessary due to failed induction $(\mathrm{p}=0.243)$.

\section{Maternal side effects/complications and neonatal outcome}

The overall incidence of maternal complications was significantly greater in Group A compared to Group B (31.8 vs. 2.0\%, p < 0.001 ; $\mathrm{OR}=22.6,95 \% \mathrm{CI}=5.3$ to 97.1 ). Women in Group A more frequently suffered from vomiting (14.0 vs. $1.0 \%, \mathrm{p}<0.001)$ and fever $(11.2$ vs. $0.0 \%, p=0.001)$. However these side-effects were symptoms of low intensity and short duration, which disappeared in less than one hour. No administration of intravenous antibiotics and anti-inflammatory drugs for fever was necessary. Although tachysystole was recorded for 13 (12.1\%) women in Group A and 9 (9.0\%) women in Group B ( $p=0.522)$, no case of hyperstimulation was reported in either group. Seven women in Group A and one woman in Group B required red blood cell transfusions because hemoglobin levels dropped below $8 \mathrm{~g} / \mathrm{dL}$ $(p=0.067)$. All women requiring transfusion had an initial hemoglobin level below $9.5 \mathrm{~g} / \mathrm{dL}$. All but one in Group A had undergone Caesarean sections. In the last case blood loss was related to perineal trauma due to operative delivery. No case of serious atonal bleeding was recorded in either group. No uterine rupture or other serious clinical incident was observed among any of our patients.

Neonatal Apgar scores at first and fifth minute were similar between groups. Most importantly, the frequency of low Apgar scores $<7$ at fifth minute did not differ significantly between groups $(\mathrm{p}=0.194)$. Nine $(8.4 \%)$ neonates in Group $A$ and four (4.0\%) neonates in Group B were transferred to intensive neonatal care unit (NICU) due to respiratory distress. Admission rate to NICU was not significantly different between groups $(\mathrm{p}=0.243$ ).

\section{Discussion}

\section{$\nabla$}

Our prospective cohort study compared two prostaglandin analogues, misoprostol and dinoprostone, as vaginal agents to labor induction in post-term singleton uncomplicated pregnancies with unfavorable cervix. Based on our results, we confirm that misoprostol administration presents certain advantages for obstetric practice. Single dose misoprostol was found to be more effective than single dose dinoprostone in inducing labor. Compared with Group A, more women in Group B needed a second vaginal dose of prostaglandin or oxytocin infusion in order to proceed to labor. Moreover, misoprostol alone as a single or double vaginal dose was found to be more effective than dinoprostone alone in inducing labor without oxytocin administration. Overall, the rate of successful induction of labor did not differ between groups. Failure of progress of labor was also similar between groups. Vaginal delivery, operative vaginal delivery and Caesarean section rates were not significantly different between groups. Time interval from induction to delivery however, was significantly shorter by misoprostol use. Though emergency Caesarean section due to fetal distress was more frequent in Group A, low Apgar scores $<7$ at first and fifth minute and neonatal NICU admissions did not differ significantly between groups. Maternal complications by misoprostol use were significantly higher but not serious.

The great picture is that misoprostol is a potent uterine stimulant, capable of inducing labor in a short time. For women who did not respond to misoprostol alone, labor was more difficult to be achieved and these women even after oxytocin administration had a low vaginal delivery rate and a high Caesarean section rate. On the other hand, dinoprostone performed better in a longer time frame and was more effective in achieving vaginal delivery after oxytocin administration. The difference in successful induction rate between the two agents after oxytocin administration did not reach statistical significance, however. This might be due to lack of power in women receiving oxytocin for labor induction as we have had only 16 cases in this subgroup of Group A. Despite potent uterine stimulation, tachysystole was not more frequent by misoprostol use and hyperstimulation was absent in our study. Yet, fetal distress that led to Caesarean section was more common in the misoprostol group. The reasons for this are unclear. Fetal distress in the misoprostol group was not corroborated by findings in the neonatal outcome, which was no different between groups. In our study fetal distress CTG was not reviewed "post hoc", after the decision for emergency Caesarean section was taken by the attending obstetrician. These assessments are subjective clinical judgments inevitably subject to imperfection and must be recognized as such. However our study being open-label is liable to bias. The high rate of fetal distress CTG in the misoprostol group might reflect lack of experience with misoprostol use, prejudice regarding its safety and reluctance to go on with labor in the setting of milder CTG anomalies than those described in the study protocol. In general, no protocol violations were reported. We assume that high conformity with study protocol was made possible due to its proximity to everyday clinical practice. The dosage and administration route of misoprostol correspond to the currently reported most frequently used regimen [15]. The timeline followed and the administration of oxytocin as a subsequent step both relate to common practices of obstetricians for labor induction.

Misoprostol has been extensively studied for numerous potential applications in obstetric practice over the last 20 years, and especially for its effectiveness in cervical ripening prior to labor augmentation $[4,21,22]$. According to previous reports, misoprostol was intravaginally administrated at various regimes of $25 \mu \mathrm{g}$ or $50 \mu \mathrm{g}$, as a single agent, and was compared to PGE2 gel or placebo. In those studies, a tachysystole rate of 4 to $37 \%$, a significantly lesser use of oxytocin and a shorter average time from induction to delivery was observed, with no adverse intrapartum or perinatal outcome [23-25]. A meta-analysis carried out by Sanchez-Ramos confirmed the safety and efficacy of intravaginal misoprostol as an agent for cervical ripening in labor induction in post-term pregnancies, although there was a significant heterogeneity among the studies due to the different doses of medications and controls [25]. Kramer et al. showed that high tachysystole rates are dependent on high dosages of misoprostol (more than $100 \mu \mathrm{g}$ ) administered every 4 hours, while the lowest rates of tachysystole are recorded with a misoprostol dose between 25 and $50 \mu$ repeated after 3-4 hours [26]. However, the safest dose for satisfactory neonatal outcome is $25 \mu$ g every 3 hours $[4,11,27$, 28]. Oral administration of misoprostol in various dosages has also been widely studied and generally was found to be effective and safe $[8,12,13,29]$. Misoprostol use has been implicated in uterine rupture risk in women with previous surgery on the uterus, but the specific magnitude of risk, though not precisely known, is in any case low; according to a meta-analysis by Plaut et al., misoprostol use was associated with a $5.6 \%$ uterine rupture rate compared with $0.2 \%$ when no induction agents were used in women attempting vaginal birth after Caesarean section [30]. In 
addition to its low cost, misoprostol in comparison to other available prostaglandins is not affected by ambient temperature and does need not refrigeration, has less effect on the cardiovascular and bronchial tree-smooth musculature and can be administrated in patients who are asthmatic and hypertensive [14].

These advantages make it particularly appealing for developing countries and since 2000 misoprostol is officially recommended by World Health Organization (WHO) for induction of labor [5]. Yet, it still lacks approval by national drug regulatory authorities and Societies of Obstetricians and Gynecologists, with few exceptions, such as Canada [3]. However, misoprostol is worldwide widely used for cervical ripening and labor induction in term and post-term pregnancies. Misoprostol is the single most commonly used drug for labor induction in Switzerland, most frequently administered vaginally in a single dose of $50 \mu \mathrm{g}$ at a dose interval range from 4 to 6 hours [15]. Also in Germany most obstetricians use misoprostol for labor induction, because they find it effective, well accepted by patients, established/well proven in clinical practice and cost-effective [16]. In both countries the main reasons given by obstetricians for not using misoprostol for labor induction are legal concerns or non-availability rather than lack of scientific evidence. Moreover, most of current nonusers would use it if misoprostol were to be licensed for this indication and commercially available $[15,16]$. The image regarding misoprostol use for labor induction in Greece is obscure. In clinical trial context, our results are consistent with another Greek study on the same issue [7]. Although opinions and practices of Greek obstetricians have not been formally studied, it seems that misoprostol is very frequently portrayed as a dangerous option for labor induction, a malpractice that should be avoided. The unregistered use of misoprostol that might take place could be potentially more harmful. Recently published guidelines of Hellenic Society of Obstetrics and Gynecology do not advocate misoprostol use for labor induction in viable pregnancies. We feel that the registration of misoprostol with National Drug Organizations for labor induction or other currently offlabel indications would enhance its safe use and certainly increase its availability. Provider training would logically follow. Our study presents certain limitations. It was not randomized, yet no significant differences arose between groups in baseline characteristics. Furthermore, its open-label character may have interfered in clinical decisions. For example fetal distress may have been overdiagnosed in misoprostol group. Clinical decisions were taken by the most part by a single person for each participant, the attending obstetrician. The study included only low risk pregnancies. The strength of our study relies on its prospective character, which allowed for the implementation of a strict standardized protocol with no violations. The protocol of the study determined the administration of pharmacological agents at predefined time intervals and sequence according to specified criteria. Yet, it remained close to everyday clinical practice.

\section{Conclusion}

\section{$\nabla$}

Our prospective cohort study compared two prostaglandin analogues, misoprostol and dinoprostone, as vaginal agents to labor induction in post-term singleton uncomplicated pregnancies. Based on our results, we confirm that misoprostol administration presents clear advantages for obstetric practice. Misoprostol alone as a single or double vaginal dose was found to be more effective than dinoprostone alone in inducing labor without oxyto- cin administration. Time interval from induction to delivery was significantly shorter by misoprostol use. Misoprostol use was shown to be safe, with no serious maternal complications and no adverse neonatal outcomes. Multiple clinical trials support the effectiveness and safety of this cost-effective drug for labor induction. In order to limit its unregistered and potentially more harmful use, misoprostol should be approved with a clear statement from national medical societies.

\section{Conflict of Interest}

\section{$\nabla$}

The authors declare that they have no competing interests.

\section{References}

1 Martin JA, Hamilton BE, Ventura SJ et al. Births: final data for 2010. Natl Vital Stat Rep 2012; 61: 1-72

2 American College of Obstetricians and Gynecologists; Society for Maternal-Fetal Medicine. Obstetric care consensus No. 1: safe prevention of the primary cesarean delivery. Obstet Gynecol 2014; 123: 693-711

3 Leduc D, Biringer A, Lee L; Society of Obstetricians and Gynaecologists of Canada. Induction of labour. J Obstet Gynaecol Can 2013; 35: 840-860

4 ACOG Committee on Practice Bulletins - Obstetrics. Practice Bulletin No 107: Induction of labor. Obstet Gynecol 2009; 114 (2 Pt 1): 386-397

5 WHO. WHO recommendations for induction of labour. Geneva: World Health Organization; 2011. Online: http://apps.who.int/iris/bitstream/ 10665/44531/1/9789241501156_eng.pdf; last access: 30.05.2015

6 Zeng $X$, Zhang Y, Tian Q et al. Efficiency of dinoprostone insert for cervical ripening and induction of labor in women of full-term pregnancy compared with dinoprostone gel: a meta-analysis. Drug Discov Ther 2015; 9: 165-172

7 Papanikolaou EG, Plachouras N, Drougia A et al. Comparison of misoprostol and dinoprostone for elective induction of labour in nulliparous women at full term: a randomized prospective study. Reprod Biol Endocrinol 2004; 2: 70

8 Rasheed R, Alam AA, Younus $S$ et al. Oral versus vaginal misoprostol for labour induction. J Pak Med Assoc 2007; 57: 404-407

9 Silfeler DB, Tandogan B, Ayvaci $H$ et al. A comparison of misoprostol, controlled-release dinoprostone vaginal insert and oxytocin for cervical ripening. Arch Gynecol Obstet 2011; 284: 1331-1337

10 Loto OM, Ikuomola AA, Ayuba II et al. Comparative study of the outcome of induction of labor using $25 \mu \mathrm{g}$ and $50 \mu \mathrm{g}$ of vaginal misoprostol. J Matern Neonatal Med 2012; 25: 2359-2362

11 Wing DA, Brown R, Plante LA et al. Misoprostol vaginal insert and time to vaginal delivery: a randomized controlled trial. Obstet Gynecol 2013; 122: 201-209

12 Rouzi AA, Alsibiani S, Mansouri N et al. Randomized clinical trial between hourly titrated oral misoprostol and vaginal dinoprostone for induction of labor. Am J Obstet Gynecol 2014; 210: 56.e1-56.e6

13 Rahman H, Pradhan A, Kharka L et al. Comparative evaluation of 50 microgram oral misoprostol and 25 microgram intravaginal misoprostol for induction of labour at term: a randomized trial. J Obstet Gynaecol Can 2013; 35: 408-416

14 Weeks $A D$, Fiala $C$, Safar P. Misoprostol and the debate over off-label drug use. BJOG 2005; 112: 269-272

15 Krause E, Malorgio S, Kuhn A et al. Off-label use of misoprostol for labor induction: a nation-wide survey in Switzerland. Eur J Obstet Gynecol Reprod Biol 2011; 159: 324-328

16 Voigt F, Goecke TW, Najjari L et al. Off-label use of misoprostol for labor induction in Germany: a national survey. Eur J Obstet Gynecol Reprod Biol 2015; 187: 85-89

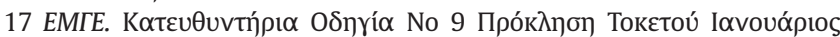
2014 [Hellenic Society of Obstetrics and Gynecology. Guideline No 9 Labor Induction January 2014]. Januar 2014: 71-79. Online: http:// www.hsog.gr/files/proklisi_toketou2.pdf; last access: 30.05.2015

18 Talaulikar VS, Arulkumaran S. Failed induction of labor: strategies to improve the success rates. Obstet Gynecol Surv 2011; 66: 717-728

19 Cohen WR, Friedman EA. Management of Labor. Baltimore: University Park Press; 1983

20 Rouse DJ, Owen J, Hauth JC. Active-phase labor arrest: Oxytocin augmentation for at least 4 hours. Obstet Gynecol 1999; 93: 323-328 
21 Tang J, Kapp N, Dragoman $M$ et al. WHO recommendations for misoprostol use for obstetric and gynecologic indications. Int J Gynaecol Obstet 2013; 121: 186-189

22 Hofmeyr GJ, Gülmezoglu AM, Pileggi C. Vaginal misoprostol for cervical ripening and induction of labour. Cochrane Database Syst Rev 2010; 10: CD000941

23 Crane JM, Butler B, Young DC et al. Misoprostol compared with prostaglandin E2 for labour induction in women at term with intact membranes and unfavourable cervix: a systematic review. BJOG 2006; 113: 1366-1376

24 Austin SC, Sanchez-Ramos L, Adair CD. Labor induction with intravaginal misoprostol compared with the dinoprostone vaginal insert: a systematic review and metaanalysis. Am J Obstet Gynecol 2010; 202: 624. e1-624.e9

25 Sanchez-Ramos L, Kaunitz AM, Delke I. Labor induction with 25 microg versus 50 microg intravaginal misoprostol: a systematic review. Obstet Gynecol 2002; 99: 145-151
26 Kramer RL, Gilson GJ, Morrison DS et al. A randomized trial of misoprostol and oxytocin for induction of labor: Safety and efficacy. Obstet Gynecol 1997; 89: 387-391

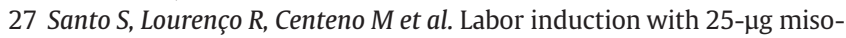
prostol vaginal capsules. Gynecol Obstet Invest 2009; 68: 272-275

28 Wing DA, Miller H, Parker L et al. Misoprostol vaginal insert for successful labor induction: a randomized controlled trial. Obstet Gynecol 2011; 117: 533-541

29 Adair $C D$, Weeks JW, Barrilleaux S et al. Oral or vaginal misoprostol administration for induction of labor: a randomized, double-blind trial. Obstet Gynecol 1998; 92: 810-813

30 Plaut MM, Schwartz ML, Lubarsky SL. Uterine rupture associated with the use of misoprostol in the gravid patient with a previous cesarean section. Am J Obstet Gynecol 1999; 180: 1535-1542 